\title{
A Critical Appraisal of the Ideology of Monogamy’s Influence on HIV Epidemiology
}

\author{
Chris Kenyon ${ }^{1,2 *}$, Robert Colebunders ${ }^{3}$, Sipho Dlamini², \\ Herman Meulemans ${ }^{3}$, Sizwe Zondo ${ }^{4}$ \\ ${ }^{1}$ STI Unit, Institute of Tropical Medicine, Antwerp, Belgium \\ ${ }^{2}$ Division of Infectious Diseases and HIV Medicine, Department of Medicine, University of Cape Town, Cape Town, \\ South Africa \\ ${ }^{3}$ University of Antwerp, Antwerpen, Belgium \\ ${ }^{4}$ Department of Psychology, Rhodes University, Grahamstown, South Africa \\ Email: "ckenyon@itg.be
}

Received 28 January 2016; accepted 19 March 2016; published 22 March 2016

Copyright (C) 2016 by authors and Scientific Research Publishing Inc.

This work is licensed under the Creative Commons Attribution International License (CC BY).

http://creativecommons.org/licenses/by/4.0/

cc) (i)

Open Access

\section{Abstract}

The linked ideas that all members of society should only engage in monogamous relationships and that these should all be based on romantic love are decided outliers from a historical perspective. Despite this, there is a widespread contemporary belief that monogamy based on love is the most ethical and natural form of partnering for humans-mononormativism. It has long been accepted that our values influence how we frame and interpret scientific questions. In the article we ask, using the example of mononormativism, how does an individual's sexual ethics influence how they pursue HIV epidemiology? Using a Social Intuitionalist theoretical framework, we argue that a belief in monogamy-as-normative has contributed to certain researchers dismissing the evidence that the generalized HIV epidemics in parts of Africa are due to higher rates of non-monogamy.

\section{Keywords}

HIV Epidemiology, Concurrency, Polygamy, Mononormativity, Social-Intuitionalism

\section{Introduction}

Two species of essentialism have retarded a fuller HIV epidemiology. The first can be viewed as a form of sexual essentialism. This has been the idea embedded in many forms in Western societies that sex is a natural force that is eternally unchanging, asocial, and transhistorical. In contrast, Rubin has cogently argued that "the con-

${ }^{*}$ Corresponding author.

How to cite this paper: Kenyon, C., Colebunders, R., Dlamini, S., Meulemans, H. and Zondo, S. (2016) A Critical Appraisal of the Ideology of Monogamy's Influence on HIV Epidemiology. World Journal of AIDS, 6, 16-26.

http://dx.doi.org/10.4236/wja.2016.61003 
crete institutional forms of sexuality at any given time and place are products of human activity. They are imbued with conflicts of interest and political maneuver, both deliberate and incidental” [1]. An example of this process that is relevant to HIV epidemiology is the emergence and later global spread of a system of socially imposed monogamy in Europe in the middle ages. With time this system transformed into a mononormativist value programme, which held monogamy to be universally normative. We define mononormativism as the belief that monogamy or serial monogamy as the most ethical form of sexual partnering.

The second form of essentialism is that of science which does not examine its underpinning values. Gunnar Myrdral noted how cultural influences "pose the questions we ask; influence the facts we seek; [and] determine the interpretation we give these facts" [2]. The theory of social intuitionalism builds on this perspective by showing how people make moral judgements largely based on intuitions that are shaped whilst they, as children, take part in the practices and custom complexes of their culture. People try to hold attitudes, beliefs and theories of causation, which are consistent with existing self-definitional beliefs. A key point here is that people's willingness to accept and use data depends on whether or not it challenges their "sacred values" [3]. It is likely that for many people moral intuitions pertaining to sexuality such as mononormativity are included in these core values. If this were true then it would be instructive to explore how our value-systems around sexuality affect our formulation of research questions, data gathering and interpretation in the field of sexually transmitted diseases. Little has been published on this topic. This paper explores the impact of mononormativity on HIV epidemiology and argues that certain authors do reveal a mononormativist bias. This prejudice has influenced their decision to dismiss, as racist, theories that the generalized HIV epidemics in Africa are due, in large part, to higher rates of non-monogamy. The first part of the paper will explore the historical origins of Monogamy-as-aUniversal-Norm (MUN) and the evidence that it operates as a value programme. The second part will evaluate the evidence that mononormativism has influenced HIV epidemiology.

\subsection{Part 1: History of Monogamy and MUN}

Numerous pieces of biological evidence, such as sexual dimorphism [4], sexual bimaturism [5], mitochondrial versus Y-chromosomal phylogenetics [6], testicle size [7], and genetic clustering [8] suggest that humans tend towards a moderate amount of non-monogamy. This is backed up by the fact that a large proportion of societies through time have condoned a version of polygamy. Polygamy for example was recorded in 850 of the 1170 societies documented in Murdock's Ethnographic Atlas [9]. Polygamy is especially common among the elite males of highly stratified societies [9]. A striking exception to this process has been the construction of the system of Socially Imposed Monogamy (SIM) in the highly stratified states of Western Europe in the late middle Ages.

MacDonald [10] argues that the dominant reason underpinning the rise of SIM in Western Europe was the emergence and dominance of the Christian Church as a powerful institution that was able to impose monogamy on the secular nobility. By the 12th century the ideology of lifetime-monogamy-as-the-only-ethical-form-of-sexualpartnering, had been imposed on essentially all members of society [11]. This sexual morality would go on to survive the Reformation and "medieval sexual morality would become the paradigm for modern Western assumptions about human sexuality that remain by and large intact" [11]. Mononormativity continued to exert a significant effect during the 20th century's sexual revolution in the West. Although characterized by significant changes in sexual ethics, such as discarding the Christian guilt associated with sexual enjoyment, ethical sexual behaviour was still largely constrained within monogamous relationships-albeit now more numerous, but mostly serially arranged monogamous relationships.

The close interactions between Christianity, liberalism and European imperialism were key to the diffusion and imposition of SIM [12]. Thus, European imperialism was responsible for the spread and dominant position accorded to Christianity around the world, and Christianity would in turn catalyze the widespread moral condemnation of polygamy that arose in multiple centers around the world [12]. Judaism in Europe would ban polygamy in 1100 in response to Christian pressure [10]. In 1880, polygamy was legislated against in Japan; in 1935 polygamy was banned in Thailand, and in China in 1953, for Hindus in India in 1955, in Nepal in 1963 and in Tunisia 1956 [13]. There are numerous examples of brutal suppression of groups that practiced polygamy, such as the Anabaptists and the Mormons [10] [14].

\subsubsection{Contemporary Mononormativism}

The relationship between Christianity and liberal-humanism is more complex. Gray has argued that at the heart 
of the humanist philosophies of liberalism and Marxism is "the transformation of the Christian doctrine of salvation into a project of universal human emancipation" [15]. When the details of this universal human emancipation project were fleshed out, numerous norms of local European cultural origin were (often subconsciously) smuggled in. It was in this way that the Christian-inspired practice of universal monogamy-for-life came to be regarded in secular Western thinking as the only acceptable form of sexual partnering [5] [16].

In the course of the 19th and 20th Centuries, the justificatory strategy for regarding monogamy as the only ethical form of sexual partnering switched from the Christian arguments explicated above to include other beliefs such as the idea that romantic love should be the foundation of sexual relationships [17] [18]. Although both the type and justificatory strategy of monogamy have changed in this new era, there is not much evidence that the commitment to monogamy in Western societies has diminished. Thus, surveys in the United States from the United States National Opinion Research Centre Surveys on Extramarital Sex have found that a high proportion of the American population believe that extramarital sex by married persons is always or almost always wrong-96\% in 1973 and 98\% in 1996 [19].

Rubin argues that a general hierarchical sexual value system in England and the United States was codified in the late 19th century [1]. "According to this system, sexuality that is 'good', 'normal', and 'natural' should ideally be heterosexual, marital, monogamous, reproductive, and non-commercial... Any sex that violates these rules is 'bad', 'abnormal', or 'unnatural'” [1]. Although this value system is contested and varies by location, it still operates as a dominant value system in much of the world. Mononormativism is best viewed as operating within this broader system.

\subsubsection{Challenging Contemporary Mononormativism}

Evidence from a variety of sources challenges contemporary mononormativism. In addition to the biological and historical data presented above, research in neuropsychology is providing a new lens on human reproductive and attachment behaviour. A range of sources point to there being three different but interrelated brain systems with corresponding behaviours that orchestrate reproduction in humans (and many other mammals) [20]. These are the sex drive which evolved to motivate individuals to seek a range of mating partners; attraction/romantic love which evolved to provide motivation to individuals to prefer and pursue specific partners; and attachment which evolved to ensure individuals remained together long enough to complete parenting duties. These three behavioural systems appear to be based on brain systems that are largely distinct yet interrelated.

Current brain imaging investigations in humans indicate that the neural correlates for attachment are distinct from those for early-stage intense romantic love in humans [21]. There is little disagreement about the existence of a sex drive and a propensity to form long term attachments in all known human societies. There has been more debate about the universality of romantic love with some arguing that it was a cultural construct, which emerged in acts of courtly love in the Middle Ages in Europe [22] [23]. However a systematic review of a standardized sample of 166 societies found that romantic love is a cross-cultural human universal [24]. What does differ, and often differs dramatically between societies are the cultural norms that mediate and regulate these three reproductive systems [25]. In much of the non-Western world marriages are arranged based on familial interests rather than on romantic love between the individuals [25]. Detailed ethnographic studies from various locations have demonstrated that the way love is thought of and how it manifests in sex and marriage is culturally mediated in ways quite different to the West [26] [27]. There are also multiple examples where it is regarded as normal for romantic love to occur outside of long-term relationships. According to Luepnitz [28], considering the full range of practices through history, it is decidedly uncommon for romantic love to be viewed as the basis for a long-term relationship/marriage. It was in the late 18th and early 19th centuries that requited love and the related freedom for men and women to choose their marriage partner became the basis of marriage [29]. Thus, human societies have found many different ways to provide room for romantic love, sex and longterm attachment.

\subsubsection{Ethics of Monogamy and Non-Monogamy}

There are numerous forms of sexual partnering such as polyamory or polygamy that have distinct foundational values to monogamy [14]. For example, many polyamorists define fidelity not as sexual exclusivity but as faithfulness to the promises and agreements made about a relationship. Gender equality and non-possessiveness are other important values for various polyamorist groupings. The value systems underpinning monogamy and forms of multiple partnering are examples of incommensurability in values. Neither can be judged as more or 
less ethical. Sartre and De Beauvoir's famously open relationship lasted 51 years [30] and it is difficult to find a sense in which it was unethical. For compelling arguments as to how polygamy is not inherently sexist see Willey [31] and Murray [32].

\subsubsection{Conceptualizing Mononormativism as a Value Programme}

What is meant by a value-programme? McMurtry [33] explains that, "values, when joined into an overall structure of thinking, whether conscious or largely unconscious in formation, make up a value system. A value system connects together goods that are affirmed and bads that are repudiated as an integrated way of thinking and acting in the world.... A value system or ethic becomes a program when its assumed structure of worth rules out thought beyond it." He goes on to state that in the pure-type case value programme, "all people enact its prescriptions and functions as presupposed norms of what they ought to do. All assume its value designations ... as given... In a strange incoherence of the programmed mind, the commands of the system are seen both as freely chosen and as laws of nature" [33].

Anderson [34] finds evidence that mononormativism operates in this way. He interviewed 40 British heterosexual male university students in long-term relationships and found evidence of monogamies hegemonic cultural dominance. Although 26 had "cheated" on their partners, all 40 regarded monogamy as the ideal personal and cultural relationship model. All described themselves as monogamous. Anderson concludes that the ideology of monogamy is so hegemonic that it is regarded as the only natural form of partnering and that his participants therefore "craft their personal and social identities as monogamous, even though many of them have extradyadic sex" [34].

If we accept the argument that there is nothing intrinsically unethical about non-monogamous arrangements and the extensive evidence that forms of non-monogamy are not unnatural for humans then it is hard to explain why polygamy remains banned in all developed countries of the world [35]. This is particularly the case if we recall that forms of non-monogamy are integral parts of various religions [14] and that freedom of religious worship has been codified in the Bills of Rights of most of these countries.

In some of these countries any form of non-monogamy is illegal. In Canada for example the law states that "any kind of conjugal union with more than one person at the same time" is illegal [36]. The monogamy laws in the United States are particularly fundamentalist: convicted polygamists are incarcerated, no "practicing polygamists" may immigrate to the country [37] and in 23 states it is a criminal offense for a married person to have consensual sex outside their marriage. The combination of the suppression of non-monogamy and the absence of significant opposition to this suppression is but one example of how mononormativism operates as a value programme-particularly in the developed world.

The reasons given for the banning of polygamy and the promotion of monogamy are not dissimilar to those used to advance other value programmes in that they generally assume as given that monogamy is the only or the most ethical form of sexual partnering. Examples of this kind of reasoning come from the Anglican Church's Lambeth Conferences. In 1958, conference resolution 120 stated: "The Conference bears witness to the truth that monogamy is the divine will, testified by the teaching of Christ himself, and therefore true for every race of men” [38]. This was reinforced in the 2008 Lambeth conference where article 114 resolved: "In the case of polygamy, there is a universal standard-it is understood to be a sin" [39].

In the case of the codification of marriage laws in South Africa, "it was taken as self-evident that the Christian form of marriage was the only one that could be recognized in law and that polygyny, like bride wealth, was incompatible with this" [40].

\subsubsection{The Ban on Polygamy in the USA}

Ertman offers an interesting interpretation of the underlying reasons for the United States of America's ban on polygamy in the 19th Century [41]. She argues that part of the reason was that Mormons were accused of racial treason for adopting a marital form which, though natural for "Asiatic and African" people, was so "barbaric" for whites that it produced a new species so degenerate that it endangered white supremacy [41].

Thus the argument used to ban polygamy in the 1862 Anti-Bigamy Act was that polygamy was a practice of primitive people such as the "Hottentots," a social "evil" and on a par with slavery- "one of the twin relics of barbarism" [41]. In the leading Supreme Court case challenging this ban (Reynolds v. United States), the court concluded that polygamy was "odious among the northern and western nations of Europe," and "almost exclusively a feature of the life of Asiatic and African people" [41]. Medical experts claimed that Mormon polygamy 
created "a new race of effete men... (with) primitive characteristics like licentiousness, laziness, childishness, and submissiveness to despotism" [41]. Polygamy was therefore criminalized in part due to its association with African and Asian people and fears for weakening of the white race. The constitutionality of the anti-polygamy laws was most recently challenged in the Utah Supreme Court in 2006. Based in part on the "continuing vitality" of the Reynolds v. United States case, four out of the five judges voted to uphold the law [42].

France was the latest country to ban polygamy, and did so 1993 . The government's argument was simply that polygamy was a foreign custom that was a threat to French society. Implicit in this view was the assumption that no "indigenous French" could reasonably choose a polygamous marriage [43]. Hortefeux, the Interior Minister, was later to propose that polygamists should be stripped of their French citizenship [44].

Further evidence for the reach of mononormativism comes from its presence in certain multilateral agencies. For example, Kulczycki [45] argues that under President Bush, PEPFAR (The President's Emergency Plan For AIDS Relief) assumed "normative human sexual activity to be mutual monogamy within marriage.” As far as the United Nations is concerned, the General Assembly adopted the Convention on the Elimination of All Forms of Discrimination Against Women, an international bill of rights for women. Article 16 states that nations must give men and women equal rights in marriage. Polygamy is interpreted as being inconsistent with Article 16 because it extends the right of multiple spouses to men but not women [46]. In a similar vein, the African Union adopted the Protocol on the Rights of Women in Africa in 2005. Article 6 of the protocol states that "monogamy is encouraged as the preferred form of marriage" [47]. This is despite the percentage of adult women being in polygamous marriages in West African countries ranging from 28\% - 52\% [48].

\subsubsection{Survey Attitudes to Non-Monogamy}

As far as general populations around the world are concerned (excluding Africa and the Middle East), there is a widespread belief that non-monogamous partnering is unethical. There have not been many comparable multinational surveys, but one study of 24 countries which did use standardised questionnaires of representative national samples of adults, found significant variations in attitudes to premarital sex, teenage sex and homosexuality [49]. This was in contrast to the considerable agreement across cultures of the wrongness of extramarital sex. In answer to the question "Is extramarital sex wrong?" $88 \%$ worldwide answered always or almost always.

There is less data available about attitudes to polygamy itself. A national representative sample of Canadians revealed that $96 \%$ oppose polygamy [50]. Even in countries in the Middle East where polygamy is legal, the majority of the population seem to regard polygamy as problematic [51].

The attitudes to non-monogamous partnering are particularly complex in sub-Saharan Africa. In South Africa, a representative national sample in 2005, found that only a minority thought formal polygamy to be acceptable [52]. It is, however, widely regarded as normative through East and Southern Africa for men to hold main and other partners and as long as this is kept secret from the main partner [53]. The genesis of this norm may relate to the way that the absorption of Christianity was a 'hybridized' process [54]. Male fidelity and monogamy were regarded as too much of a cultural compromise and thus men who converted to Christianity were more likely to conceal their extra marital relations with "amankazana" (additional partners), but not less likely to engage in them. A similar attitude pertains to this day. A national survey in South Africa found that "the notion of having 'main' and 'other' partners came across overwhelmingly as being normative” [55]. Men who have 'kwapeni” (secret partners) on the side still regard themselves as being faithful as long as they protect their main partner by keeping the relationship and using condoms [55].

\subsection{Part 2: Mononormativism, Academia and HIV Epidemiology}

"The love of man, if considered from the standpoint of advanced civilization, can only be of a monogamic nature. From the moment when woman was recognized the peer of man, when monogamy became a law and was consolidated by legal, religious and moral considerations, the Christian nations attained a mental and material superiority over the polygamic races, and especially over Islam."

- Psychopathia Sexualis [56].

Contemporary mononormativism is far less crude than the quote above from Krafft-Ebing's 1886 textbook [56]. More recent examples of mononormativism in academic papers come from a wide range of disciplines including zoology [5], history [10] and demography [57]. Bowlby [58], Miller and Fishkin [59] are among the many psychologists and evolutionary biologists who have argued that long-term monogamous mating in humans 
is a species-universal reproductive strategy. In many spheres of psychology it is still assumed that "a long term monogamous relationship is the natural, mature goal for adult intimacy" [60].

\subsubsection{HIV, Concurrency and Mononormativity}

In the HIV field there is now a considerable amount of evidence that demonstrates that a key feature responsible for the one to two orders of magnitude difference in HIV prevalence between different countries and between different ethnic groups within countries is the differing sexual partner concurrency rates [61]-[63]. Sexual partner concurrency here is defined as an overlap in time of two or more sexual partnerships. There is good evidence that concurrency rates vary substantially between different ethnic groups [64], that the pattern of this variation follows that of variations in HIV rates [65] that the magnitude of this variation is sufficient to explain a large part of the differing HIV rates [66] and that where HIV rates have come down rapidly the key reason was a reduction in rates of concurrency [67] [68]. Nine individual-level studies have confirmed a link between concurrency and HIV transmission [69]. If we consider the way that concurrency is itself patterned in the contemporary world, this suggests that high concurrency (and hence high HIV prevalence) rates in sub Saharan Africa are predominantly determined by cultural and not socio-economic factors [70]. This is henceforth termed the HIVcultural thesis.

There has been considerable resistance to this thesis. This has come in two forms. Firstly, concurrency is acknowledged to be important in the genesis of generalized HIV epidemics, but high concurrency rates are viewed as being determined by economic rather than cultural factors [71]. Secondly, concurrency is regarded as unimportant to HIV transmission. Certainly some of the evidence behind the link between HIV and concurrency is incomplete and warrants further investigation [72]. What concerns us here is not these issues but other more normative criticisms that argue that the HIV-concurrency and HIV-cultural theses are unethical and therefore untenable. One of the most important critiques of the HIV-concurrency thesis that argues along these lines is that of Stillwaggon and colleagues. For a considerable period, Stillwaggon rejected the idea that differences in sexual behaviour are responsible for high HIV prevalence in parts of Africa. In one of her first papers on the topic entitled "Racial Metaphors: Interpreting Sex and AIDS in Africa," she argued that, "western preconceptions regarding African sexuality distorted early research on the social context of AIDS in Africa and limited the scope of preventive policies. Key works cited repeatedly in the social science and policy literature constructed a hypersexualized pan-African culture as the main reason for the high prevalence of HIV in sub-Saharan Africa" [73]. The key paper she cites as portraying this "hypersexualised pan African culture" is written by Caldwell et $a l$. [74], who argue, that there are significant differences in sexual partnering in many parts of Africa compared to low HIV prevalence regions of the world. Caldwell et al. make clear their belief that the norms underpinning these systems of sexuality are "no more right or wrong... than the Eurasian system" [72]. A more recent paper by Sawers and Stillwaggon argues that "concurrent sexual partnerships do not explain the HIV epidemics in Africa" [75]. Arguing that "sexual behaviour is not driving African epidemics," the authors accuse the proponents of the concurrency-HIV argument of evoking "widely held stereotypes about Africans that have been deeply embedded in Western culture for centuries" [73]. They end with a call "for an end (or at least a moratorium) to research on sexual behaviour in Africa of the kind discussed in this article" [73].

Similar perspectives are evident in a range of other HIV publications where papers such as that by Caldwell et al., are labeled 'racist' [76]-[79], or a “'new racism' in which 'culture', 'tradition' and 'ethnicity' perform the work previously achieved by the category of 'race'” [80].

If sexual behaviour is so dramatically varied between different human societies [9], then why are non-pejorative descriptions of difference, such as those of Caldwell et al. [72] regarded as racist/discriminatory? It is true that in the colonial period sexuality in Africa was frequently described in racist ways. It was often described as "wild, animal like, exotic, irrational and immoral" [81]. Whilst some of the anthropology of sexuality in Africa in the HIV era has once again accentuated the exotic and the lurid [82] this should not tarnish all assessments of differences in sexual behaviour with the same assessment of racism. A clue as to why descriptions of sexual behaviour difference may be regarded as problematic comes from a recent paper by Kaul et al. [83] entitled "Biological Factors that May Contribute to Regional and Racial Disparities in HIV Prevalence." In the paper they argue that "a focus on the cultural and behavioural aspects of HIV transmission tends to implicitly lay blame for infection on affected communities or individuals... Considering biological causes for these racial disparities may help to destigmatize the issue.” Their review provides no plausible biological factors that could explain the racial differences in HIV prevalence mentioned above. This does not however seem to give them cause to re- 
consider the rather misleading title to their paper. Why do they persist with favoring biological explanations when they have not found any plausible ones? A reason they give is that they look to biological explanations to "destigmatize the issue"-implying that behaviours that enhance HIV transmission are in some way stigmatized/immoral. Their reasoning thus seems to be that since ascribing racial difference in HIV rates to differences in sexual behaviors is stigmatizing, investigators should look for other explanations.

Stillwaggon initially blamed socioeconomic factors for the higher HIV prevalences in Africa [71] [84]. Since this explanation has been largely discredited, she now argues that biological factors such as schistosomiasis and unsafe injecting practices are responsible [73]. Although authors such as Sawers and Stillwaggon at no point state that they regard monogamy as more ethical than forms of non-monogamy, this can be inferred from their writings. Thus, if authors argue that the provision of evidence that shows that monogamy is less prevalent in parts of Africa is racist then it necessarily follows that these authors regard monogamy as more ethical.

\subsubsection{Using Social Intuitionalism to Explore the Relationship between Sexual Morality, Ideology and HIV Epidemiology}

A useful theoretical framework to explain the reluctance of numerous authors to evaluate the HIV-cultural thesis is that of social intuitionalism. Haidt, who has done a lot of work to develop the theory, explains that the central claim of the social intuitionist model is that "moral judgment is caused by quick moral intuitions and is followed (when needed) by slow, ex post facto moral reasoning” [85]. In other words, rational conscious thought serves as a way of justifying our decisions after the moral evaluation is made. One line of evidence used to back up the theory is that of experiments where participants have strong moral revulsion but are unable to provide a rational explanation for their revulsion-termed "dumbfounding." An example is asking people to imagine a brother and a sister having sex once, no harm coming of it and them both feeling that this brought them closer together as siblings. Many/most people tested have a powerful negative reaction to this scenario but struggle to explain why using rational arguments. This and other pieces of evidence argue that much of our ethical evaluations are based on unconscious, affective intuitions [83]. The utility of this theory in the field of moral judgement pertaining to issues of sexual ethics has been established in previous studies [86] [87].

Haidt explains that, "moral development is primarily a matter of the maturation and cultural shaping of endogenous intuitions. People can acquire explicit prepositional knowledge about right and wrong in adulthood, but it is primarily through participation in custom complexes of their cultures involving sensory, motor, and other forms of implicit knowledge shared with one's peers during the sensitive period of late childhood and adolescence that one comes to feel, physically and emotionally, the self-evident truth of moral propositions" [83].

Although there is not much research that has been done in this field, that which has been done supports Haidt's theory that norms pertaining to sexuality are intuitions shaped during early adolescence via participation in custom complexes [88] [89]. If this is the case, then explaining numerous authors' extreme reluctance to countenance the HIV-cultural thesis becomes easier to understand. If one has an intuition that monogamy is normative, then the HIV-cultural thesis will likely be seen as racist - one is stating that Africans are more likely to engage in unethical behaviour-concurrency. Research based on cognitive dissonance, and defence motivation theories have demonstrated how individual's willingness to use relevant information depends on whether or not their sacred values or self-definitional beliefs were threatened in doing so [90]. If mononormativism behaves as a sacred value, and if its subconscious position protects it from self-reflection, then this could produce an intuition that concurrency is immoral and hence produce a powerful bias in affected researchers thinking. The social intuitionalist and cognitive dissonance theories would then predict that these researchers would turn elsewhere to manufacture evidence to contradict the evidence that threatens their sacred values.

\section{Conclusion}

An increasing body of evidence suggests that higher concurrency rates have played an important role in the genesis of generalized HIV epidemics. These higher concurrency rates are in turn supported by norms that tolerate forms of concurrency [91]. It has been well established that if one is not open about the values that underpin one's research, then these values can sub-consciously over-determine the facts and theories one chooses to portray. If academics are not self-aware of their own sexual ideologies and the full range of different sexual moralities that humans can embrace then, in a similar way, they may disregard evidence that norms supporting concurrency are a key driver of HIV spread. Further research is needed to better understand the timing, nature, and 
determinants of the development of sexual morality in individuals in different groups. This research could then feed into locally-agreed-upon interventions to influence sexual norms in a way that results ultimately in decreased sexual-network connectivity and hence sexually transmitted disease transmissibility. Work in this field would be strengthened if it was to be conducted with increased reflexivity that acknowledged the possible influences of author's sexual ideologies on their work.

\section{Acknowledgements}

Nil.

\section{Declaration of Conflicting Interests}

Nil.

\section{References}

[1] Rubin, G. (1992) Thinking Sex: Notes for a Radical Theory of the Politics of Sexuality. In: Vance, C., Ed., Pleasure and Danger: Exploring Female Sexuality, Pandora, London, 267-293.

[2] Myrdal, G. (1944) An American Dilemma: The Negro Problem and Modern Democracy. Harper Bothers, New York.

[3] Haidt, J. (2001) The Emotional Dog and Its Rational Tail: A Social Intuitionist Approach to Moral Judgment. Psychological Review, 108, 814-834. http://dx.doi.org/10.1037/0033-295X.108.4.814

[4] Reno, P.L., Meindl, R.S., McCollum, M.A. and Lovejoy, C.O. (2003) Sexual Dimorphism in Australopithecus Afarensis Was Similar to That of Modern Humans. Proceedings of the National Academy of Sciences, 100, 9404-9409. http://dx.doi.org/10.1073/pnas.1133180100

[5] Barash, D. and Lipton, J. (2001) The Myth of Monogamy: Fidelity and Infidelity in Animals and People. Henry Holt and Company, New York.

[6] Dupanloup, I., Pereira, L., Bertorelle, G., Calafell, F., Prata, M., Amorim, A., et al. (2003) A Recent Shift from Polygyny to Monogamy in Humans Is Suggested by the Analysis of Worldwide Y-Chromosome Diversity. Journal of Molecular Evolution, 57, 85-97. http://dx.doi.org/10.1007/s00239-003-2458-X

[7] Harcourt, A., Harvey, P., Larson, S. and Short, R. (1981) Testis Weight, Body Weight and Breeding System in Primates. Nature, 293, 55-57. http://dx.doi.org/10.1038/293055a0

[8] Xue, Y. (2005) Recent Spread of a Y-Chromosomal Lineage in Northern China and Mongolia. American Journal of Human Genetics, 77, 1112-1116. http://dx.doi.org/10.1086/498583

[9] Hartung, J. (1982) Polygyny and Inheritence of Wealth. Current Anthropology, 23, 1-12. http://dx.doi.org/10.1086/202775

[10] MacDonald, K. (1995) The Establishment and Maintenance of Socially Imposed Monogamy in Western Europe. Politics and the Life Sciences, 14, 3-23.

[11] Brundage, J. (1987) Law, Sex, and Christian Society in Medieval Europe. University of Chicago Press, Chicago. http://dx.doi.org/10.7208/chicago/9780226077895.001.0001

[12] Zeitsen, M. (2008) Polygamy-A Cross-Cultural Analysis. Berg Publishers, Oxford.

[13] Schneidel, W. (2008) Monogamy and Polygyny in Greece, Rome, and World History. Princeton/Stanford Working Papers in Classics, Stanford.

[14] Harmer-Dionne, E. (2008) Once a Peculiar People: Cognitive Dissonance and the Suppression of Mormon Polygamy as a Case Study Negating the Belief-Action Distinction. Stanford Law Review, 50, 1295-1347. http://dx.doi.org/10.2307/1229287

[15] Gray, J. (2002) Straw Dogs. Thoughts on Humans and Other Animals. Farrar, Straus \& Giroux, New York.

[16] Kenyon, C. and Zondo, S. (2011) Why Do Some South African Ethnic Groups Have Very High HIV Rates and Others not? African Journal of AIDS Research, 10, 51-62. http://dx.doi.org/10.2989/16085906.2011.575548

[17] Singer, I. (1987) The Nature of Love: The Modern World. University of Chicago Press, Chicago.

[18] Delger, C. (1980) At Odds: Women and the Family in America from the Revolution to the Present. Oxford University Press, New York.

[19] Smith, T. (1997) Changes in Families and Family Values. National Opinion Research Center, University of Chicago, Chicago.

[20] Fisher, H., Aron, A. and Brown, L. (2006) Romantic Love: A Mammalian Brain System for Mate Choice. Philosophi- 
cal Transactions of the Royal Society B, 361, 2173-2186. http://dx.doi.org/10.1098/rstb.2006.1938

[21] Fisher, H., Aron, A. and Brown, L. (2005) Romantic Love: An fMRI Study of a Neural Mechanism for Mate Choice. The Journal of Comparative Neurology, 493, 58-62. http://dx.doi.org/10.1002/cne.20772

[22] Rougemont, D. (1974) Love in the Western World. M. Belgion Trans., Harper, New York.

[23] Fisher, H. (1995) The Nature and Evolution of Romantic Love. In: Jankowiak, W., Ed., Romantic Passion, Columbia University Press, New York, 103-134.

[24] Jankowiak, W. and Fischer, E. (1992) A Cross-Cultural Perspective on Romantic Love. Ethnology, 31, 149-155. http://dx.doi.org/10.2307/3773618

[25] De Munck, V. (1988) Romantic Love and Sexual Behavior: Perspectives from the Social Sciences. Praeger, Westport.

[26] De Munck, V. (1998) Lust, Love and Arranged Marriages in Sri Lanka. In: De Munck, V., Ed., Romantic Love and Sexual Behavior: Perspectives from the Social Sciences, Praeger, Westport.

[27] Moore, R. (1998) Love and Limerance with Chinese Characteristics: Student Romance in the PRC. In: De Munck, V., Ed., Romantic Love and Sexual Behavior: Perspectives from the Social Sciences, Praeger, Westport.

[28] Luepnitz, D. (1988) The Family Interpreted: Feminist Theory in Clinical Practice. Basic Books, New York.

[29] Glenn, E.N. (1992) From Servitude to Service Work: Historical Continuities in the Racial Division of Paid Reproductive Labor. Signs, 18, 1-43. http://dx.doi.org/10.1086/494777

[30] Appignanesi, L. (1995) Simone de Beauvoir. Haus Publishers, London.

[31] Willey, A. (2006) “Christian Nations”, “Polygamic Races” and Women’s Rights: Toward a Genealogy of Non/Monogamy and Whiteness. Sexualities, 9, 530-546. http://dx.doi.org/10.1177/1363460706069964

[32] Murray, C. (1994) Legal Eye: Is Polygamy Wrong? Agenda, 22, 37-41. http://dx.doi.org/10.2307/4065733

[33] McMurtry, J. (1998) Unequal Freedoms: The Global Market as an Ethical System. Garammond Press, Toronto.

[34] Anderson, E. (2010) “At Least with Cheating There Is an Attempt at Monogamy”: Cheating and Monogamism among Undergraduate Heterosexual Men. Journal of Social and Personal Relationships, 27, 851-872. http://dx.doi.org/10.1177/0265407510373908

[35] Brandon, M. (2010) Monogamy: The Untold Story. ABC-CLIO, Santa Barbara.

[36] Beaman, L. (2004) Church, State and the Legal Interpretation of Polygamy in Canada Nova Religio. Nova Religio, 8, 20-31. http://dx.doi.org/10.1525/nr.2004.8.1.20

[37] Ertman, M. (2010) Race Treason: The Untold Story of America’s Ban on Polygamy. Columbia Journal of Gender and Law, 19, 287-366. http://dx.doi.org/10.2139/ssrn.1270023

[38] Lambeth Conference (1958) Resolutions of the Lambeth Conference 1958. Anglican Communion Office.

[39] Lambeth Conference (2008) Resolutions of the Lambeth Conference 2008. Anglican Communion Office.

[40] Kaganas, F.M. (1991) Law, Women and the Family: The Question of Polygyny in a New South Africa. Acta Juridica, 116-129.

[41] Davis, A.D. (2010) Regulating Polygamy: Intimacy, Default Rules, and Bargaining for Equality. Columbia Law Review 110 .

[42] (2006) Utah Supreme Court. State v. Holm, Utah LEXIS 91.

[43] Henley, J. (2001) I Can't Say to a Wife of 20 Years She Has to Go. The Guardian. http://www.guardian.co.uk/world/2001/may/09/jonhenley

[44] Dickey, C. (2010) Sarkozy’s Right-Wing Rubicon. Newsweek.

[45] Kulczycki, A. (2007) Ethics, Ideology, and Reproductive Health Policy in the United States. Studies in Family Planning, 38, 333-351. http://dx.doi.org/10.1111/j.1728-4465.2007.00145.x

[46] United Nations General Assembly (1979) Convention on the Elimination of All Forms of Discrimination against Women. UN, Geneva.

[47] African Union (2011) The Maputo Protocol of the African Union: An Instrument for the Rights of Women in Africa, 2006. www.gtz.de

[48] Cook, C. (2007) Polygyny Did the Africans Get It Right? Journal of Black Studies, 38, 232-250. http://dx.doi.org/10.1177/0021934705285695

[49] Widmer, E., Treas, J. and Newcomb, R. (1998) Attitudes toward Nomarital Sex in 24 Countries. The Journal of Sex Research, 35, 349-358. http://dx.doi.org/10.1080/00224499809551953

[50] Bibby, R. (2004) The Future Families Project: A Survey of Canadian Hopes and Dreams. http://www.vifamily.ca/node/177 
[51] Moaddel, M. (2006) The Saudi Public Speaks: Religion, Gender, and Politics. International Journal of Middle East Studies, 38, 79-108. http://dx.doi.org/10.1017/S0020743806412265

[52] Amoateng, Y. (2006) On Marrying, Mixing and Everything Else: The Changing Face of Family Life in South Africa. HSRC Review, 4, 4-5.

[53] Jana, M., Nkambule, M., Tumbo, D., Goldstein, S. and Weiner, R. (2008) One Love: Multiple and Concurrent Sexual Partnerships in Southern Africa. A Ten-Country Research Report. Soul City. www.onelovesouthernafrica.org/wp.../01/mcp-reportwith-cover-final.pdf

[54] Delius, P. and Glaser, C. (2004) The Myths of Polygamy: A History of Extra-Marital and Multi-Partnership Sex in South Africa. South African Historical Journal, 50, 84-114. http://dx.doi.org/10.1080/02582470409464797

[55] Parker, W., Makhubele, B., Ntlabati, P. and Connolly, C. (2007) Concurrent Sexual Partnerships amongst Young Adults in South Africa. Challenges for HIV-Prevention Communication. Centre for AIDS Development, Research and Evaluation, CADRE.

http://www.comminit.com/c-change-picks/content/concurrent-sexual-partnerships-amongst-young-adults-south-africachallenges-hiv-preventi

[56] Krafft-Ebing, R. (1924) Psychopathia Sexualis: With Especial Reference to the Antipathic Sexual Instinct: A Medico-Forensic Study. F. Rebman Trans. (1886), Physicians and Surgeons Book Company, New York.

[57] Pogrebov, I. (2006) Prevalence and Assessment of Polygamy in Uzbekistan. Russian Social Science Review, 47, 57-64. http://dx.doi.org/10.2753/SOR1061-0154450404

[58] Bowlby, J. (1969) Attachment and Loss (Vol. 1). Basic Books, New York.

[59] Miller, L. and Fishkin, S. (1997) On the Dynamics of Human Bonding and Reproductive Success: Seeking a "Windows" on the “Adapted for” Human-Environmental Interface. In: Simpson, J. and Kenrick, D.T., Eds., Evolutionary Social Psychology, Erlbaum, Hillsdale, 197-236.

[60] Kenyon, C.R., Osbak, K., Buyze, J., Johnson, S. and van Lankveld, J. (2014) Variations of Sexual Scripts Relating to Concurrency by Race, Class, and Gender in South Africa. The Journal of Sex Research, 1-9.

[61] Mah, T. and Halperin, D. (2010) Concurrent Sexual Partnerships and the HIV Epidemics in Africa: Evidence to Move Forward. AIDS Behavior, 14, 11-16. http://dx.doi.org/10.1007/s10461-008-9433-x

[62] Kenyon, C., Buyze, J. and Colebunders, R. (2013) HIV Prevalence by Race Co-Varies Closely with Concurrency and Number of Sex Partners in South Africa. PLOS ONE, 8, e64080. http://dx.doi.org/10.1371/journal.pone.0064080

[63] Kenyon, C. and Colebunders, R. (2012) Strong Association between Point-Concurrency and National Peak HIV Prevalence. International Journal of Infectious Diseases, 16, e826-e827. http://dx.doi.org/10.1016/j.ijid.2012.05.008

[64] Kenyon, C., Dlamini, S., Boulle, A., White, R. and Badri, M. (2009) A Network-Level Explanation for the Differences in HIV Prevalence in South Africa’s Racial/Ethnic Groups. African Journal of AIDS Research, 8, 243-254. http://dx.doi.org/10.2989/AJAR.2009.8.3.1.922

[65] Morris, M., Epstein, H. and Wawer, M. (2010) Timing Is Everything: International Variations in Historical Sexual Partnership Concurrency and HIV Prevalence. PLoS ONE, 5, e14092.

[66] Morris, M., Kurth, A., Hamilton, D., Moody, J. and Wakefield, S. (2009) Concurrent Partnerships and HIV Prevalence Disparities by Race: Linking Science and Public Health Practice. American Journal of Public Health, 99, 1023-1031. http://dx.doi.org/10.2105/AJPH.2008.147835

[67] Kirby, D. (2008) Changes in Sexual Behaviour Leading to the Decline in the Prevalence of HIV in Uganda: Confirmation from Multiple Sources of Evidence. Sexually Transmitted Infections, 84, ii35-ii41. http://dx.doi.org/10.1136/sti.2008.029892

[68] Halperin, D., Mugurungi, O., Hallett, T., Muchini, B., Campbell, B., et al. (2011) A Surprising Prevention Success: Why Did the HIV Epidemic Decline in Zimbabwe? PLoS Medicine, 8, e1000414. http://dx.doi.org/10.1371/journal.pmed.1000414

[69] Epstein, H. and Morris, M. (2011) Concurrent Partnerships and HIV: An Inconvenient truth. Journal of the International AIDS Society, 14, 13. http://dx.doi.org/10.1186/1758-2652-14-13

[70] Kenyon, C., Boulle, A., Badri, M. and Asselman, V. (2010) “I Don’t Use a Condom (with my Regular Partner) Because I Know That I'm Faithful, but with Everyone Else I Do": The Cultural and Socioeconomic Determinants of Sexual Partner Concurrency in Young South Africans. Journal of Social Aspects of HIVIAIDS, 7, 35-43. http://dx.doi.org/10.1080/17290376.2010.9724967

[71] Abdool Karim, S., Churchyard, G., Abdool Karim, Q. and Lawn, S. (2009) HIV Infection and Tuberculosis in South Africa: An Urgent Need to Escalate the Public Health Response. The Lancet, 374, 921-933. http://dx.doi.org/10.1016/S0140-6736(09)60916-8

[72] Mah, T. and Shelton, J. (2011) Concurrency Revisited: Increasing and Compelling Epidemiological Evidence. Journal 
of the International AIDS Society, 14, 33. http://dx.doi.org/10.1186/1758-2652-14-33

[73] Stillwaggon, E. (2003) Racial Metaphors: Interpreting Sex and AIDS in Africa. Development and Change, 35, 809-832. http://dx.doi.org/10.1111/j.1467-7660.2003.00330.x

[74] Caldwell, J., Caldwell, P. and Quiggin, P. (1989) The Social Context of AIDS in Sub-Saharan. Africa. Population and Development Review, 15, 185-234. http://dx.doi.org/10.2307/1973703

[75] Sawers, L. and Stillwaggon, E. (2010) Concurrent Sexual Partnerships Do Not Explain the HIV Epidemics in Africa: A Systematic Review of the Evidence. Journal of the International AIDS Society, 13, 34. http://dx.doi.org/10.1186/1758-2652-13-34

[76] Petros, G., Airhihenbuwa, C., Simbayi, L., Ramlagan, S. and Brown, B. (2006) HIV/AIDS and “Othering” in South Africa: The Blame Goes On. Culture, Health \& Sexuality, 8, 66-77. http://dx.doi.org/10.1080/13691050500391489

[77] Saethre, E. and Stadler, J. (2009) A Tale of Two "Cultures”: HIV Risk Narratives in South Africa. Medical Anthropology, 28, 268-284. http://dx.doi.org/10.1080/01459740903073414

[78] Crewe, M. and Aggleton, P. (2003) Racism, HIV/AIDS and Africa: Some Issues Revisited. South African Journal of International Affairs, 10, 139-149. http://dx.doi.org/10.1080/10220460309545417

[79] Kalipeni, E. (2004) HIV and AIDS in Africa: Beyond Epidemiology. Blackwell, Malden, 18.

[80] Macleod, C. and Durrheim, K. (2002) Racializing Teenage Pregnancy: “Culture” and "Tradition” in the South Africa Scientific Literature. Ethnic and Racial Studies, 25, 778-801. http://dx.doi.org/10.1080/0141987022000000268

[81] Gausset, Q. (2001) AIDS and Cultural Practices in Africa: The Case of the Tonga (Zambia). Social Science \& Medicine, 57, 509-518. http://dx.doi.org/10.1016/S0277-9536(00)00156-8

[82] Green, E. (2003) Rethinking AIDS Prevention; Learning from Successes in Developing Countries. Praeger Publishers, Westport.

[83] Kaul, R., Cohen, C., Chege, D., Yi, T., Tharao, W., McKinnon, L., et al. (2011) Biological Factors That May Contribute to Regional and Racial Disparities in HIV Prevalence. American Journal of Reproductive Immunology, 65, 317324. http://dx.doi.org/10.1111/j.1600-0897.2010.00962.x

[84] Stillwaggon, E. (2006) AIDS and the Ecology of Poverty. Oxford University Press, Oxford.

[85] Greene, J. and Haidt, J. (2002) How (and Where) Does Moral Judgment Work? Trends in Cognitive Sciences, 6, 517523. http://dx.doi.org/10.1016/S1364-6613(02)02011-9

[86] Haidt, J., Koller, S. and Dias, M. (1993) Affect, Culture, and Morality, or Is It Wrong to Eat Your Dog? Journal of Personality and Social Psychology, 65, 613-628. http://dx.doi.org/10.1037/0022-3514.65.4.613

[87] Haidt, J. and Hersh, M. (2001) Sexual Morality: The Cultures and Emotions of Conservatives and Liberals. Journal of Applied Social Psychology, 31, 191-221. http://dx.doi.org/10.1111/j.1559-1816.2001.tb02489.x

[88] Simon, R., Eder, D. and Evans, C. (1992) The Development of Feeling Norms Underlying Romantic Love among Adolescent Females. Social Psychology Quarterly, 55, 29-46. http://dx.doi.org/10.2307/2786684

[89] O’Sullivan, L.F. and Meyer-Bahlburg, H.F. (2003) African-American and Latina Inner-City Girls' Reports of Romantic and Sexual Development. Journal of Social and Personal Relationships, 20, 221-238.

[90] Harmon-Jones, E. and Mills, J. (1999) Cognitive Dissonance: Progress on a Pivotal Theory in Social Psychology. American Psychological Association, Washington DC. http://dx.doi.org/10.1037/10318-000

[91] Kenyon, C. (2015) The Prevalence of Sexual Partner Concurrency Is Not Correlated with Markers of Poverty or Gender Inequality: An Ecological Analysis. World Journal of AIDS, 5, 322-327. http://dx.doi.org/10.4236/wja.2015.54035 